\title{
Measurement and Modeling of Aqueous Solutions' Viscosity of Hydrolyzed Acrylic Fiber
}

\author{
Tiangui Wang ${ }^{\mathrm{a}}$, Chuang $\mathrm{Li}^{\mathrm{b}}$ \\ School of Chemistry and Chemical Engineering, Henan University of Technology, Zhengzhou \\ 450001, China \\ atgwang2006@126.com, b1244379873@qq.com
}

Keywords: Polyacrylonitrile, hydrolysis, viscosity, model.

\begin{abstract}
The aim of the study is to determine the dependency of the viscosity of the aqueous solutions of hydrolyzed acrylic fiber on the concentration and temperature. Aqueous solutions of hydrolyzed acrylic fiber were prepared by hydrolysis of the waste fiber in water at elevated temperature. The solution viscosities of various solid contents at different temperatures were determined by means of a rotary viscometer. The results were fitted with the known models and two following equations were shown excellent to correlate the viscosities, concentration and temperature in the range of $20-95^{\circ} \mathrm{C}$ and $15-82 \%(w t)$ of the solid content.
\end{abstract}

$\eta=\exp \left(-7.0645+\frac{2892.81}{T}+6.755 x\right)$ or $\eta=\exp (12.058-0.0312 T+6.76 x)$

\section{Introduction}

Lots of waste fibers come out during the processing and uses of acrylic fibers and used clothing made up of the acrylics are discarded constantly. As the dominant component of acrylic fibers, polyacrylonitrile cannot be thermally degraded, moulded or fired (which gives out toxic matters). Therefore, finding out the ways to utilize the scrap stuff is significant. Some processes have been shown to be effective and valuable and among them hydrolysis following with producing specialty chemicals is a common practice. There are three kinds of hydrolysis processes of polyacrylonitrile, that is, acid catalytic hydrolysis [1], base catalytic hydrolysis [2,3] and autoclave non-catalytic hydrolysis [4]. The hydrolysis produces backbones of polyacrylonitrile with various groups other than nitrile, such as amide, carboxyl, and so on. Depending on the hydrolysis extent, hydrolysis media and parameters, many end products can be made and super-absorbent materials [5] and drilling aid agents [6] are two typical represents. This article is a part of the study to improve an autoclave hydrolysis process of acrylic fibers and mainly introduce viscosity measurement and modeling of aqueous solutions of hydrolyzed acrylic fiber.

\section{Materials and Methods}

Ten grams of acrylic fiber (provided by FENGQIU JIXING Chemicals Co Ltd., Henan Province, China) was mixed with $60 \mathrm{~mL}$ water in an autoclave of $100 \mathrm{~mL}$ volume and the contents were heated to $210{ }^{\circ} \mathrm{C}$ for 3 hours. After cooling to room temperature, the contents were taken out and as the crude hydrolysis solution. The solid percentage was determined by vaporizing water at $110{ }^{\circ} \mathrm{C}$. A rotary viscometer (Model NDJ-1, SHANGHAI) was used to measure the viscosity of the samples of various solid contents at different temperature. The results were shown in Table 1. 
Table 1 Results of viscosity measurement $(\mathrm{Pa} \cdot \mathrm{s})$

\begin{tabular}{ccccccc}
\hline Temperature & \multicolumn{7}{c}{ Solid content (wt\%) } \\
\cline { 2 - 6 }$\left({ }^{\circ} \mathrm{C}\right)$ & 14.71 & 19.95 & 36.79 & 59.61 & 74.64 & 82.09 \\
\hline 20 & 56 & 92 & 135 & 915 & 1640 & 4250 \\
30 & 25 & 70 & 102 & 693 & 1270 & 3700 \\
40 & 18 & 62 & 90 & 475 & 1020 & 3250 \\
50 & 15 & 52 & 77 & 300 & 810 & 2650 \\
60 & 10 & 36 & 56 & 215 & 590 & 2100 \\
70 & 7 & 26 & 45 & 145 & 480 & 1750 \\
80 & 5 & 21 & 38 & 127 & 390 & 1300 \\
90 & 3 & 17 & 33 & 114 & 320 & 820 \\
95 & 3 & 14 & 28 & 108 & 280 & 740 \\
\hline
\end{tabular}

\section{Results and Discussions}

Table 1 indicates that the viscosity of the aqueous solutions of the hydrolyzed acrylic fibers increases with the solid content rising, however, decreases with temperature going up. It has been shown that polyacrylonitrile degrades and nitriles hydrolyze completely in water at $210{ }^{\circ} \mathrm{C}$ for 3 hours [7]. The hydrolysis solutions contain carboxylic acid, ammonium carboxylate, amide, imide, et al. There are many model equations to represent the relationship of the viscosity of polyelectrolyte solutions, temperature and concentration [8-12]. Some of those are listed in table 2. Among them Eq. (1)-(3) correlate viscosity and temperature; Eq. (4)-(9) correlate viscosity and concentration; Eq. (10)-(14) correlate viscosity, concentration and temperature simultaneously. Except for $\mathrm{T}$ representing temperature and $\mathrm{x}$ representing concentration, all other characters are parameters of different meanings. Most of the equations are empirical or semi-empirical, minors base on theoretical analysis. The equations in Table 2 were checked to fit the data in Table 1 and the results indicate that Eq. (10) correlates viscosity, concentration and temperature excellently. F-test shows highly significant. The final form is shown in Eq. (15). Equation (2) correlates viscosity and temperature well and Eq. (5) fits viscosity and concentration satisfactorily, however, it needs to change to Eq. (16). Figures 1, 2 and Table 3, 4 show related illustrations and information.

$$
\begin{aligned}
& \eta=\exp \left(-7.0645+\frac{2892.81}{T}+6.755 x\right) \\
& \eta=\exp (a+b x) \text { or } \ln \eta=a+b x
\end{aligned}
$$

Where $\eta$ is viscosity (Pa.s); T is temperature (K); $x$ is concentration (solute mass fraction)

Equation (1) is an Arrhenius empirical equation. It cannot be used in the situation of high temperature and high concentration although it is said that it has exact theoretical basis. Equations (2) and (3) look to be similar as Eq. (1) and they can be seen as modified forms of Eq. (1). Nevertheless, through improving, Eq. (2) can accurately predict viscosity values at elevated temperature. Equation (4) bases partly on theory. With some improvement, it can be used to predict the viscosity change of a polymer solution with the concentration. However, it doesn't adequately predict the aqueous solution viscosity of hydrolyzed acrylic fibers at elevated temperature. Simulating calculation found that among Eq. (4) to (9), only Eq. (5), after transforming to Eq. (16), correlated the viscosity and the concentration fabulously. Statistically, Eqs. (7), (8) and (9) correlated the viscosity and the concentration significantly. Nonetheless, partial viscosity values calculated are far away from the experimental ones and even some are negative, which is unreasonable obviously. Table 4 indicates that parameter $\boldsymbol{b}$ changes hardly with temperature and $\boldsymbol{a}$ downs with temperature rising. Clearly, Eq. (16) cannot be extrapolated to dilute solutions because $\eta \neq \eta_{w}$ at $x=0$. Figure 2 also shows that among the nine runs, the last four points appear linearity quite well. However, the first three departs from a straight line substantially. Figure 3 proves that parameter $\boldsymbol{a}$ and temperature in Table 4 appear a straight line which is fitted by Eq. (17). Substitution of Eq. (17) for parameter $\boldsymbol{a}$ in Eq. (16) gives Eq. (18) which correlates the aqueous solution viscosity of hydrolyzed acrylic fibers, temperature and concentration adequately and the accuracy is same as that of Eq. (15). 


$$
\begin{aligned}
& a=12.058-0.0312 T \\
& \eta=\exp (12.058-0.0312 T+6.76 x)
\end{aligned}
$$

Table 2 Model equations of correlating viscosity, temperature and concentration

\begin{tabular}{lll}
\hline \multicolumn{1}{l}{$\eta-\mathrm{T}$} & \multicolumn{1}{c}{$\eta-\mathrm{x}$} & $\eta$-(T, x) \\
\hline (1) $\eta=\eta_{\infty} \exp (a / T)$ & (4) $\eta=\eta_{w}\left(1+\frac{a x}{1+b x^{0.5}}+c x\right)$ & (10) $\eta=\exp \left(a+\frac{b}{T}+c x\right)$ \\
(2) $\eta=\eta_{\infty} \exp \left(\frac{a}{T}+\frac{b}{T^{2}}\right)$ & (5) $\eta=\eta_{w} \exp \left(a_{1} x+a_{2} x^{2}+\cdots\right)$ & (11) $\eta=a_{0} \exp \left(\frac{E}{R T}+a_{1} x+a_{2} x^{2}\right)$ \\
(3) $\eta=\eta_{\text {ref }} \exp \left(\frac{E_{a}}{R}\left(\frac{1}{T}-\frac{1}{T_{\text {ref }}}\right)\right)$ & (6) $\eta=\frac{\eta_{w} \exp (a x)}{1+b x}$ & (12) $\ln \eta=a_{0}+\frac{a_{1}+a_{2} x}{T-T_{1}-T_{2} x}$ \\
& (7) $\eta=\eta_{w}\left(1+a_{1} x^{0.5}+a_{2} x\right)$ & (13) $\eta=\eta_{\infty} x^{a} \exp \left(\frac{E}{R T}\right)$ \\
(8) $\eta=\eta_{w}\left(1+a_{1} x^{0.5}+a_{2} x+a_{3} x^{2}\right)$ & (14) $\eta=\eta_{\infty} \exp \left(\frac{(a+b / T) x}{100-(c+d T) / x}\right)$ \\
(9) $\eta=\eta_{w}\left(1+a_{1} x+a_{2} x^{2}\right)$ &
\end{tabular}
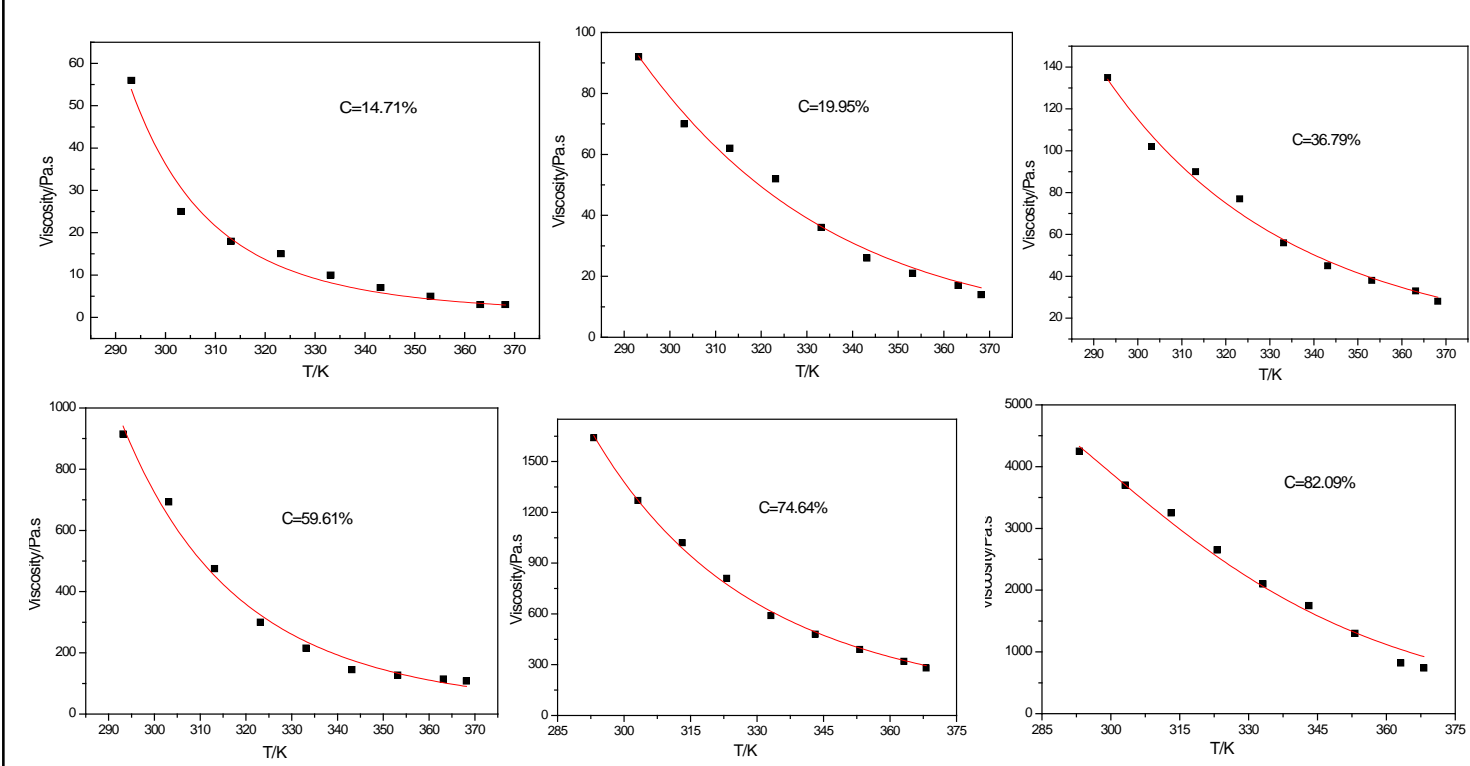

Fig. 1 Relationship of viscosity and temperature for the solution of different concentrations (The lines were produced by Eq.2)

Table 3 Fitted parameters of the solution of different concentrations by Eq. (2)

\begin{tabular}{cccrc}
\hline \multirow{2}{*}{$\begin{array}{c}\text { Solid content } \\
(\mathrm{wt} \%)\end{array}$} & $\eta_{\infty}$ & $\boldsymbol{a}$ & $\boldsymbol{b}$ & \multicolumn{1}{c}{$\mathrm{R}^{2}$} \\
\cline { 2 - 5 } & 22.34 & -4681.81 & 1.45 & 0.970 \\
14.71 & $1.23 \mathrm{E}-5$ & 7330.28 & -788216.96 & 0.982 \\
19.95 & $5.27 \mathrm{E}-3$ & 4000.20 & -300881.89 & 0.988 \\
36.79 & $8.11 \mathrm{E}-3$ & 3474.52 & -16394.91 & 0.988 \\
59.61 & $3.70 \mathrm{E}-2$ & 3962.80 & -241391.13 & 0.997 \\
74.64 & $3.78 \mathrm{E}-6$ & 11004.20 & -1.43 & 0.986 \\
82.09 & & & & \\
\hline
\end{tabular}


Table 4 Fitted parameters of the solution of different concentrations by Eq. (16)

\begin{tabular}{cccc}
\hline \multirow{2}{*}{$\begin{array}{c}\text { Temperature } \\
\left({ }^{\circ} \mathrm{C}\right)\end{array}$} & \multicolumn{3}{c}{ Parameters and Adj. R-Square $\left(\mathrm{R}^{2}\right)$} \\
\cline { 2 - 4 } & $\boldsymbol{a}$ & $\boldsymbol{b}$ & $\mathrm{R}^{2}$ \\
\hline 30 & 3.0676 & 6.12 & 0.971 \\
40 & 2.4571 & 6.69 & 0.965 \\
50 & 2.2276 & 6.72 & 0.955 \\
60 & 2.0611 & 6.57 & 0.946 \\
70 & 1.6478 & 6.75 & 0.944 \\
80 & 1.2826 & 6.93 & 0.939 \\
90 & 1.0347 & 6.97 & 0.942 \\
95 & 0.7365 & 7.03 & 0.935 \\
& 0.6334 & 7.02 & 0.950
\end{tabular}
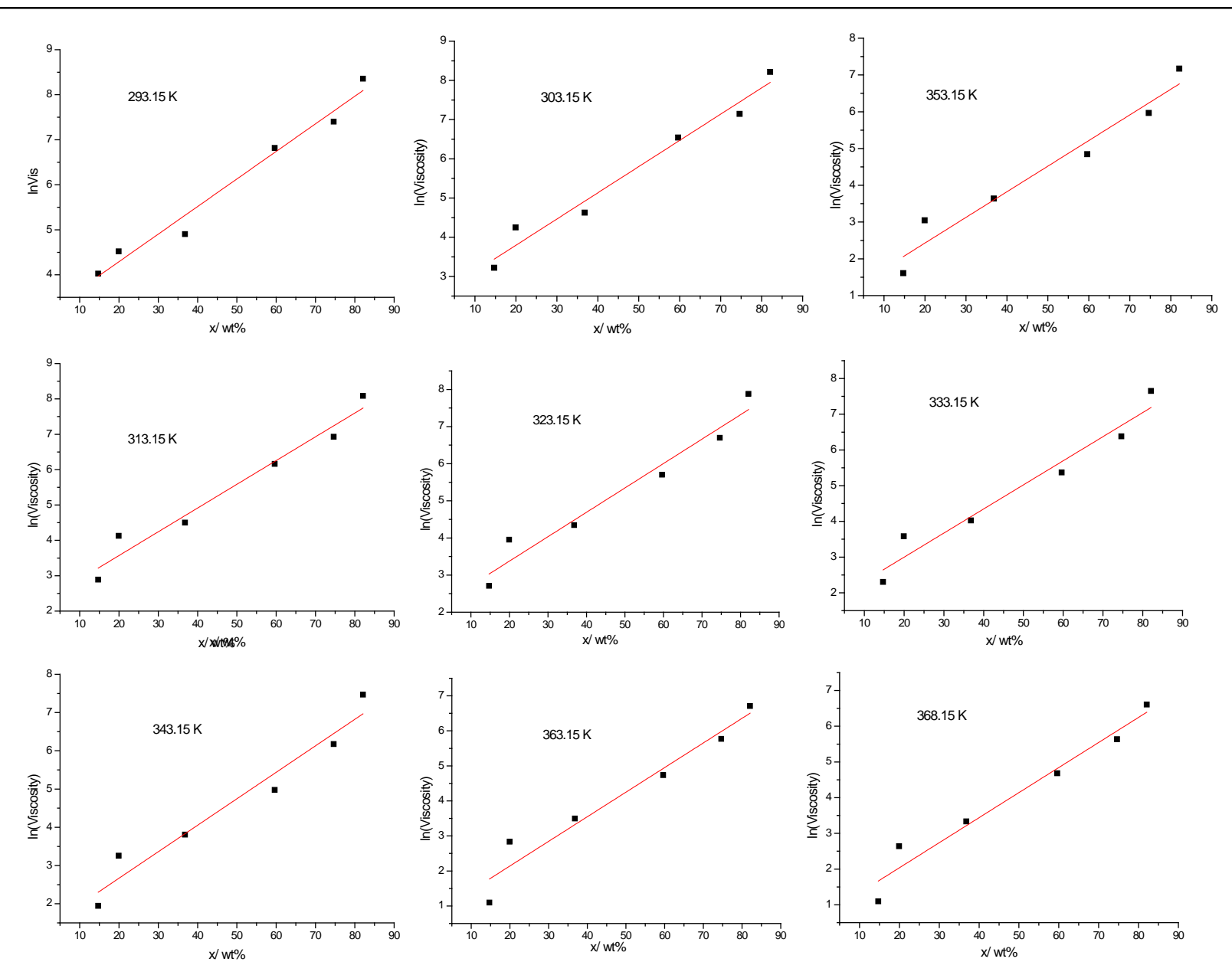

Fig. 2 Relationship of the viscosity and the concentration at different temperatures (The lines were produced by Eq.16) 


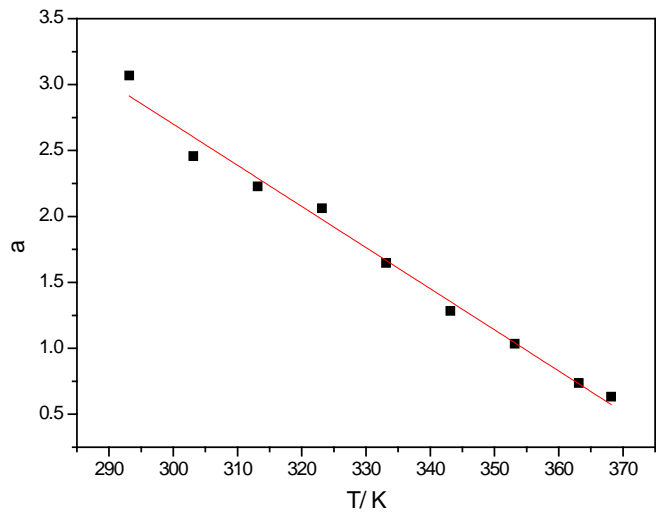

Fig. 3 Relationship of parameter $\boldsymbol{a}$ and temperature in Table (4)

\section{Conclusions}

The viscosity of the aqueous solutions of hydrolyzed acrylic fibers drops with temperature rising, however, goes up with the increase of solid content. Their relationship can be adequately represented by the following equations (Eq. (15) and Eq. (18)).

$$
\eta=\exp \left(-7.0645+\frac{2892.81}{T}+6.755 x\right) \text { or } \eta=\exp (12.058-0.0312 T+6.76 x)
$$

\section{References}

[1] J. van der Geer, J.A.J. Hanraads, R.A. Lupton, The art of writing a scientific article, J. Sci. Commun. 163 (2000) 51-59.

[1] L.B. Krentsel, Y.V. Kudryavtsev, A.I. Rebrov, A.D. Litmanovich and N.A. Platé, Acidic hydrolysis of polyacrylonitrile: effect of neighboring groups, Macromolecules 34(2001)5607-5610

[2] I.V. Ermakov, A.I. Rebrov, A.D. Litmanovich and N.A. Platé, Alkaline hydrolysis of polyacrylonitrile, 1 Structure of the reaction products, Macromol. Chem. Phys. 201(2000)1415-1418

[3] O. Sanli, Homogeneous hydrolysis of polyacrylonitrile by potassium hydroxide, Eur. Polym. J. 26(1990)9-13.

[4] M. Siskin, R.Y. Saleh, G.A. Knudsen, U.S. Patent 5312898. (1994)

[5] G.S. Mann, Process for the continuous production of superabsorbent polymer from PAN: U.S. Patent 6590040. (2003)

[6] D.F. Kong, Study on the preparation of anti-temperature and anti-salt drilling loss control agent based on waste acrylonitrile fibers. M.S. thesis, Dongying, China University of Petroleum (East China), 2013

[7] T.F. Liu, J.F. Zhang, X.Y. Lyu, Kinetics of non-catatalyzed hydrolysis of polyacrylonitrile in near-critical water, Acta Polym. Sinica (2011) 107- 113

[8] C.H. Gao, Viscosity of partially hydrolyzed polyacrylamide under shearing and heat, J. Petrol. Explor. Prod. Technol. 3 (2013)203-206

[9] C.H. Gao, Empirical correlations for viscosity of partially hydrolyzed Polyacrylamide, J. Petrol. Explor. Prod. Technol. 4(2014)209-213

[10]J. Sukpisan, J. Kanatharana, A. Sirivat and S.Q. Wang, The specific viscosity of partially hydrolyzed polyacrylamide solutions: effects of degree of hydrolysis, molecular weight, solvent quality and temperature, J. Polym. Sci.: Part B: Polymer Physics 36(1998)743-753. 
[11]M.A. Magerramov, A.I. Abdulagatov, I.M. Abdulagatov and N.D. Azizov, Viscosity of tangerine and lemon juices as a function of temperature and concentration, Int. J. Food Sci. Technol. 42 (2007)804-818

[12]V.R.N. Telis, J. Telis-Romero, H.B. Mazzotti and A.L. Gabas, Viscosity of aqueous carbohydrate solutions at different temperatures and concentrations, Int. J. Food Prop. 10 (2007) 185-195 